\title{
Characteristics analysis of mechanical seal face based on thermo-hydrodynamic effect
}

\author{
Yuanxiang Zhang*, Yuliang Zhang \\ Key Laboratory of Air-driven Equipment Technology of Zhejiang Province, Quzhou University, Quzhou 324000, China
}

Corresponding Author Email: zhangyx@qzu.zj.cn

https://doi.org/10.18280/ijht.360332

Received: 19 December 2017

Accepted: 10 May 2018

\section{Keywords:}

thermo-hydrodynamic effect, mechanical seal, face characteristics, heat transfer characteristic

\begin{abstract}
The thermo-hydrodynamic effect of the non-contact mechanical seal includes the liquid film flow characteristics and heat transfer characteristics of the seal face. It is of great practical significance to study the effects of friction and thermal deformation on the liquid film flow characteristics and heat transfer characteristics of the mechanical seal. This paper obtains the governing equation of the liquid film flow characteristics of the mechanical seal based on the momentum conservation and mass conservation equations, and then studies the thermohydrodynamic effect mechanism of the mechanical seal face through the coupling analysis of the interactions between the mechanical seal ring and the liquid film. The research results show that the mechanical seal face is deformed under the action of friction and mechanical force, and the liquid film flow characteristics of the end face changes. The liquid film pressure of the parallel flow channel increases linearly along the axial direction, and the liquid film pressure of the non-parallel flow channel exhibits a non-linear increase in a "convex" or "concave" direction; the leakage rate of the parallel flow channel is the smallest, followed by that of the convergent flow channel and then that of the divergent one. The liquid film bearing capacity of the convergent channel is the largest and that of the divergent one is the smallest. Overall, the performance of the parallel flow channel is the most stable. When the mechanical seal face is only subjected to the friction of the liquid film, the larger the angular frequency, the smaller the thickness of the liquid film, and the more heat generated by the friction. The heat transfer coefficient of the rotating ring is much greater than that of the stationary ring, so the heat absorption of the former is also significantly higher than that of the latter. The research results can provide theoretical reference for the study of the non-contact mechanical seal mechanism and the practical application of the thermo-hydrodynamic effect.
\end{abstract}

\section{INTRODUCTION}

The mechanical seal is a device that uses the preload of the elastic element to achieve the sealing of the axial end face. It has such advantages as long life, good vibration resistance, low energy consumption and low comprehensive cost [1]. Its basic structure is shown in Fig.1. The basic components include a sealing rotating ring and a stationary ring, an elastic element, an anti-rotation element, a rotating shaft and a sealing medium, etc. [2]. The mechanical seal is an effective way to solve various leakage problems. Improving its performance can greatly save all kinds of energy and protect the ecological environment, bringing both economic and social benefits.

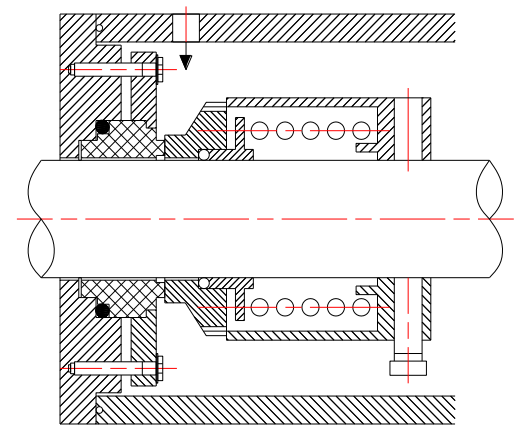

Figure 1. Mechanical seal structure
The low leakage rate and high operating cycle of a mechanical seal are mainly determined by relevant characteristics of the mechanical seal faces. The stronger the end face friction and the greater the contact stress between the end faces, the smaller the operating cycle of the mechanical seal and the higher the leakage rate [3-5]. Currently, researchers generally explain the characteristics of the mechanical seal face using the mechanism of fluid friction film formation, the exchange flow theory of boundary friction and lubrication, the dry friction mechanism and the thermohydrodynamic effect theory, etc. [6-12]. The above theories can only explain the mechanism of partial face sealing, while in practice, the end faces are under the joint action of friction, deformation, flowing deformation, corrosion and other factors. At present, theoretical analysis cannot truly reflect the seal face characteristics [13-14].

The "thermo-hydrodynamic effect" caused by the seal face waviness and temperature difference is another problem for the mechanical seal. The fluid shear between the end faces increases the surface temperature and viscosity of the liquid film, leading to differences in the lubrication performance of the liquid film in the end face gap and deformation of the end faces [15-19]. Due to the thermo-hydrodynamic effect, mechanical seals have complex problems in heat transfer, force deformation and thermal deformation [20-25]. At present, researchers mainly study the thermal deformation and phase shift THD effect of the mechanical seal face through 
theoretical derivation (fluid mechanics or thermodynamics) or various finite element numerical simulation methods, but the research progress is still very slow [26-28].

In light of the deficiencies in the above literatures, this paper discusses the patterns of the liquid film flow characteristics and the heat transfer characteristics of the mechanical seal face under the action of friction and thermal deformation. The research conclusions can provide theoretical reference for the application of non-contact mechanical seals.

\section{ANALYSIS ON THE LIQUID FILM FLOW CHARACTERISTICS OF THE MECHANICAL SEAL FACE}

\subsection{Analytical algorithm for the liquid film flow characteristic}

The mechanical seal face is deformed by friction and mechanical force during operation. Fig. 2 shows the section profiles of the flow channels after the end face is deformed. Fig.2(a) 2(d) represent the parallel flow channel, the divergent channel, the convergent channel, and the convergent-divergent channel, respectively.

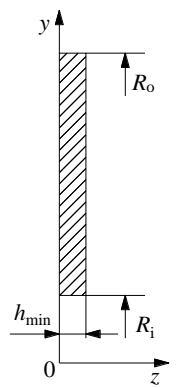

( a )

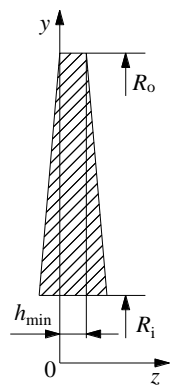

( b )

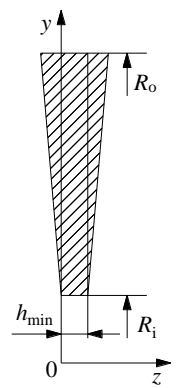

(c)

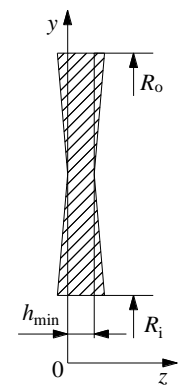

(d)
Figure 2. Section profiles of the parallel flow channel, the divergent channel, the convergent channel and the convergent-divergent channel

In the figures, hmin stands for the minimum film thickness of the liquid film, which is expressed as:

$h=h_{\min }+\left(y-R_{\mathrm{i}}\right) \cot \theta$

The governing equation for the flow of the liquid film is:

$\frac{\mathrm{d}}{\mathrm{d} Y}\left[\frac{\bar{\rho}(H+Y \tan \theta)^{3}}{\bar{\mu}} \frac{\mathrm{d} P}{\mathrm{~d} Y}\right]=0$

$\mathrm{Y}, \mathrm{H}$ and Pare dimensionless parameters, and there is:

$Y=y / b \quad H=h_{i} / b \quad P=\left(p-p_{i}\right) /\left(p_{0}-p_{i}\right) \quad \bar{\mu}=\mu / \mu_{0} \quad \bar{\rho}=\rho / \rho_{0}$

Below is the process of how the characteristics of the flow channels of different types are solved:

(1) In the parallel flow channel, the liquid film pressure $\mathrm{P} 1=\mathrm{Y}$ and $\theta=0$, so equation ( 2 ) can be simplified as: $\frac{\mathrm{d}}{\mathrm{d} Y}\left[\frac{\bar{\rho} H^{3}}{\bar{\mu}} \frac{\mathrm{d} P}{\mathrm{~d} Y}\right]=0$

The carrying capacity F1 of the liquid film is:

$F_{1}=2 \pi b^{2}\left(p_{\mathrm{o}}-p_{\mathrm{i}}\right)\left(\frac{R}{2}+\frac{1}{3}\right)+\pi b^{2} p_{\mathrm{i}}(2 R+1)$

The leakage rate $\mathrm{Q} 1$ is:

$Q_{1}=2 \pi R_{\mathrm{i}} \int_{0}^{h_{\mathrm{i}}} w_{\mathrm{y}} \mathrm{d} z=-\frac{\pi b^{3}\left(p_{\mathrm{o}}-p_{\mathrm{i}}\right)}{\mu_{0}} \frac{R H^{3}}{6 \bar{\mu}}$

(2) The carrying capacity F2 of the non-parallel flow channel is:

$F_{2}=2 \pi b^{2}\left(p_{\mathrm{o}}-p_{\mathrm{i}}\right) \Lambda+\pi b^{2} p_{\mathrm{i}}(2 R+1)$

$\Lambda=\frac{(H+\tan \theta)^{2}}{(H+\tan \theta)^{2}-H^{2}} \times\left[0.5+R-\frac{H^{2}}{\tan ^{2} \theta}\left(\frac{\tan \theta(R \tan \theta-H)}{H(H+\tan \theta)}+\ln \frac{H+\tan \theta}{H}\right)\right]$

The volume flow leakage rate $\mathrm{Q} 2$ is:

$Q_{2}=-\frac{\pi b^{3}\left(p_{\mathrm{o}}-p_{\mathrm{i}}\right)}{\mu_{0}} \frac{R H^{2} \tan \theta}{3 \bar{\mu}} \frac{(H+\tan \theta)^{2}}{(H+\tan \theta)^{2}-H^{2}}$

The liquid film pressure $\mathrm{P} 2$ is

$P_{2}=\frac{(H+\tan \theta)^{2}}{(H+\tan \theta)^{2}-H^{2}}\left[1-\left(\frac{H}{H+Y \tan \theta}\right)^{2}\right]$

(3) In the convergent-divergent channel, let the position of hmin be in Ym of the convergent-divergent channel, and the pressure distribution is

$$
\begin{aligned}
& P_{0-X}=-\frac{\bar{\mu}}{2 \rho \tan \theta_{1}} C_{11}\left(H+Y \tan \theta_{1}\right)^{-2}+C_{12} \\
& P_{X-1}=-\frac{\bar{\mu}}{2 \rho \tan \theta_{2}} C_{21}\left[H+Y \tan \theta_{1}+\left(Y-Y_{\mathrm{m}}\right) \tan \theta_{2}\right]^{-2}+C_{22}
\end{aligned}
$$

Equations (11) and (12) represent the pressure distribution when $0<\mathrm{Y}<\mathrm{Ym}$ and $\mathrm{Ym}<\mathrm{Y}<1$, respectively.

The carrying capacity F3 of the liquid film is:

$$
\begin{aligned}
F_{3}= & 2 \pi b^{2}\left(p_{\mathrm{o}}-p_{\mathrm{i}}\right)\left(\Lambda_{1}+\Lambda_{2}\right)+\pi b^{2} p_{\mathrm{i}}(2 R+1) \\
\Lambda_{1}= & {\left[\ln \frac{H+Y_{\mathrm{m}} \tan \theta_{1}}{H}+\frac{\left(R \tan \theta_{1}-H\right) Y_{\mathrm{m}} \tan \theta_{1}}{H\left(H+Y_{\mathrm{m}} \tan \theta_{1}\right)}\right] \times \frac{A C_{11}}{\tan ^{2} \theta_{1}}+C_{12}\left(R Y_{\mathrm{m}}+\frac{1}{2} Y_{\mathrm{m}}^{2}\right) } \\
\Lambda_{2}= & \frac{\left(Y_{\mathrm{m}} \tan \theta_{2}+R \tan \theta_{2}-H-Y_{\mathrm{m}} \tan \theta_{1}\right)\left(1-Y_{\mathrm{m}}\right) \tan \theta_{2}}{\left(H+Y_{\mathrm{m}} \tan \theta_{1}\right)\left(H+Y_{\mathrm{m}} \tan \theta_{1}+\tan \theta_{2}-Y_{\mathrm{m}} \tan \theta_{2}\right)} \times \frac{B C_{21}}{\tan ^{2} \theta_{2}}+ \\
& \frac{B C_{21}}{\tan ^{2} \theta_{2}} \ln \frac{H+Y_{\mathrm{m}} \tan \theta_{1}+\left(1-Y_{\mathrm{m}}\right) \tan \theta_{2}}{H+Y_{\mathrm{m}} \tan \theta_{1}}+C_{22}\left[R\left(1-Y_{\mathrm{m}}\right)+\frac{1}{2}\left(1-Y_{\mathrm{m}}^{2}\right)\right]
\end{aligned}
$$

$Q_{3}=\frac{\pi b^{3}\left(p_{\mathrm{o}}-p_{\mathrm{i}}\right)}{\mu_{0}} \frac{R A C_{11} \tan \theta_{1}}{3 \bar{\mu}}$ 


\subsection{Results and discussion}

Fig. 3 shows the pressure distribution of the liquid film in different types of gaps. Curves 1 and 2 in the figure indicate convergence gaps. hmin is both $0.002 \mathrm{~mm}$. For curve 1, $\theta=0.0002$, and for curve 2, $\theta=0.0004$; curve 3 is a convergence-divergence gap, where hmin $=0.0002 \mathrm{~mm}, \theta 1=-$ 0.0005 and $\theta 2=0.0005$; curve 4 is a parallel gap, where hmin $=0.002 \mathrm{~mm}$ and $\theta=0$; curve 5 and curve 6 are divergence gaps, where hmin is both $0.002 \mathrm{~mm}$ and for curve $5, \theta=-0.0002$, and for curve $6, \theta=-0.0004$.

It can be seen from the figure that the liquid film pressure of the parallel gap increases linearly along the $\mathrm{Y}$-axis; the pressure in the convergence gaps (1 and 2) is always greater than that in the parallel one, and it exhibits an "upward convex" distribution; the liquid film pressure in the divergence gaps is always smaller than that in the parallel one, and it exhibits a "downward concave" distribution; the pressure in the convergence-divergence gap increases slowly first and then rapidly, and on the whole, the liquid film pressure in the convergence gap is much greater than that in the divergence gap.

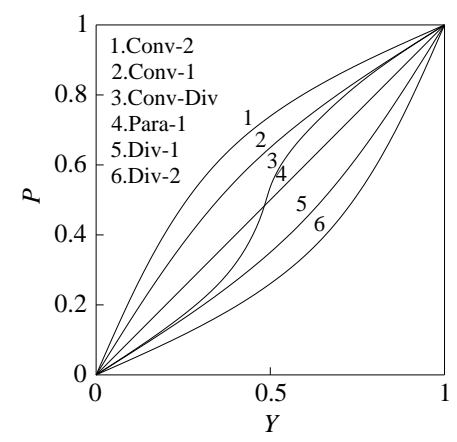

Figure 3. Liquid film pressure in different types of gaps

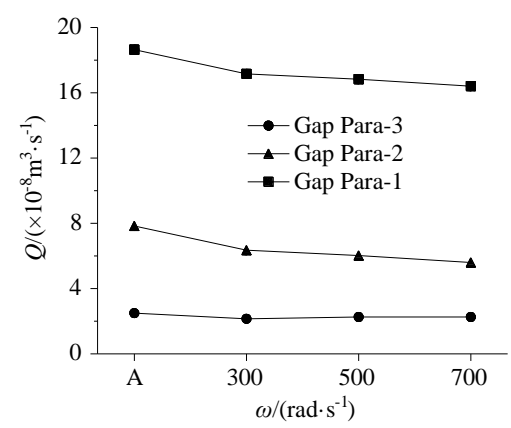

(a) Parallel flow channel

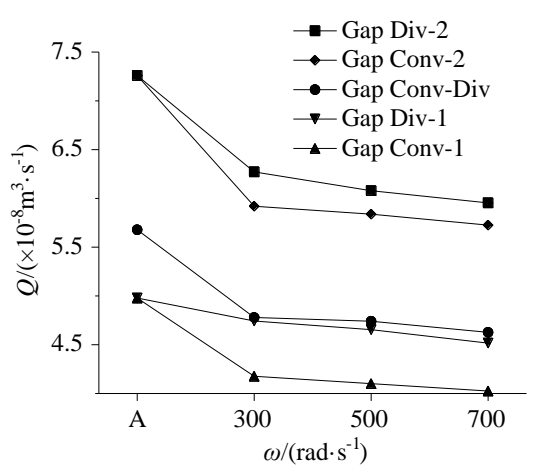

(b) Non-parallel flow channel

Figure 4. Leakage rates of the parallel flow channel and the non-parallel flow channel

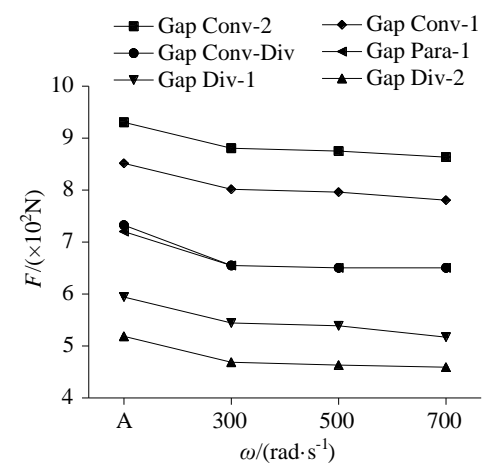

Figure 5. Carrying capacity of the liquid film in different types of flow channels

Fig.4 shows the leakage rates of the parallel flow channel and the non-parallel flow channel. As can be seen, the liquid leakage rate of the mechanical seal face is proportional to the thickness of the liquid film, and also to the pressure difference between the outer diameter and the inner diameter of the liquid film. Through comparison of the leakage rates of different flow channels, it can be found that the leakage rate of the parallel flow channel is the smallest, followed by that of the convergent channel and then that of the divergent channel.

Fig.5 shows the carrying capacity of the liquid film in different types of flow channels. As can be seen, the flow channels in terms of the liquid film carrying capacity from large to small are the convergent channel, the parallel flow channel and the divergent channel. In the convergent channel, the carrying capacity $\mathrm{F}$ is proportional to the absolute value of the angle, while in the divergent one, the former is inversely proportional to the latter. When the bearing capacity of the mechanical seal is less than the spring force, the thickness of the liquid film decreases, and ultimately the contact friction occurs between both ends of the seal, intensifying the deformation and the generation of friction heat.

\section{ANALYSIS ON THE HEAT TRANSFER CHARACTERISTICS OF THE MECHANICAL SEAL}

This section further analyzes the heat transfer characteristics of the mechanical seal. When the liquid film thickness of the seal face is constant, the heat flux density $\mathrm{q}$ and the heat generated by friction $Q_{f}$ are:

$$
\begin{aligned}
& q=\tau r \omega=\frac{\mu r^{2} \omega^{2}}{\delta} \\
& Q_{f}=\int_{R_{\mathrm{i}}}^{R_{0}} 2 \pi r q \mathrm{~d} r=\frac{\pi \mu \omega^{2}}{2 \delta}\left(R_{\mathrm{o}}^{4}-R_{\mathrm{i}}^{4}\right)
\end{aligned}
$$

When the liquid film thickness changes linearly, the thickness can be expressed as:

$\delta(r)=\delta_{\mathrm{i}}+\left(r-R_{\mathrm{i}}\right) \tan \beta$

At this time, the frictional heat $Q_{f}$ is:

$Q_{f}=\frac{\pi \mu \omega^{2}}{3 \tan ^{4} \beta}\left[2\left(\delta_{\mathrm{o}}^{3}-\delta_{\mathrm{i}}^{3}\right)+9 d\left(\delta_{\mathrm{o}}^{2}-\delta_{\mathrm{i}}^{2}\right)+18 d^{2}\left(\delta_{\mathrm{o}}-\delta_{\mathrm{i}}\right)+6 d^{3} \ln \left(\frac{\delta_{\mathrm{o}}}{\delta_{\mathrm{i}}}\right)\right]$ 
Assuming there is no leakage or other form of heat loss, all the heat generated on the end faces will be transferred to the rotating and stationary rings. Then the heat transfer coefficient of the rotating ring $\alpha_{m r}$ and that of the stationary ring $\alpha_{m s}$ can be expressed as:

$$
\begin{aligned}
& \alpha_{\mathrm{mr}}=0.135 \lambda\left[\left(0.5 \operatorname{Re}_{\mathrm{c}}^{2}+\operatorname{Re}_{\mathrm{a}}^{2}\right)\right]^{0.33} / D_{\mathrm{r}} \\
& \alpha_{\mathrm{ms}}=0.0115 \lambda \varepsilon_{1} \operatorname{Re}^{0.8} \operatorname{Pr}^{0.4} / S_{\mathrm{s}}
\end{aligned}
$$

The equation of the heat exchange between the rotating ring and the stationary ring in the seal face:

$\left\{\begin{array}{l}Q_{\mathrm{r}}=A_{\mathrm{r}} \alpha_{\mathrm{fr}}\left(\theta_{\mathrm{f}}-\theta_{\mathrm{r}}\right) \\ Q_{\mathrm{s}}=A_{\mathrm{s}} \alpha_{\mathrm{fs}}\left(\theta_{\mathrm{f}}-\theta_{\mathrm{s}}\right)\end{array}\right.$

$\mathrm{Q}_{\mathrm{r}}$ and $\mathrm{Q}_{\mathrm{s}}$ respectively represent the heat transferred to the rotating ring and the stationary ring; $\theta_{f}, \theta_{r}$, and $\theta_{s}$ respectively represent the temperature of the liquid film, of the rotating ring and of the stationary ring.

The governing equation for heat conduction is:

$$
\frac{\partial^{2} \theta}{\partial x^{2}}+\frac{\partial^{2} \theta}{\partial y^{2}}=0
$$

The general solution to equation (24) can be expressed as:

$$
\Delta \theta(x, y)=\sum_{i=1}^{\infty} B_{i}\left[\exp \left(k_{i} x\right)+\exp \left(-k_{i} x\right)\right] \cos k_{i} y
$$

According to the condition of the heat flux boundary, the above equation is transformed into:

$\Delta \theta(x, y)=\frac{2 q}{\lambda} \times \sum_{i=1}^{\infty} \frac{\left[\exp \left(k_{i} x\right)+\exp \left(-k_{i} x\right)\right] \sin k_{i} b \cos k_{i} y}{k_{i}\left[\exp \left(k_{i} L\right)-\exp \left(-k_{i} L\right)\right]\left(k_{i} b+\sin k_{i} b \cos k_{i} b\right)}$

The heat transfer characteristics of the mechanical seal are analyzed according to the above derivation. Fig. 6 shows the relationship between the heat generated by friction and the angular frequency of the mechanical seal face. The liquid film thicknesses of curves 1-3 are all $2 \mathrm{~mm}$, and that of curve 4 is $6 \mathrm{~mm} ; \theta_{1}=\theta_{4}=0, \theta_{2}=0.0005$, and $\theta_{3}=0.01$. It can be seen that when there is no direct contact between the rotating ring and the stationary one, and the friction only occurs on the liquid film of the end face, the frictional heat is proportional to the angular frequency. When $\theta$ is constant, the smaller the thickness of the liquid film is, the more heat the seal face will generate due to friction.

Fig.7 shows the relationship between the heat transfer coefficient of the rotating ring and the angular frequency. Fig. 8 shows the ratio of the heat received by the rotating ring to that by the stationary ring. As can be seen, the heat transfer coefficient of the rotating ring is proportional to the angular frequency, and the heat absorbed by the rotating one is much larger than that absorbed by the stationary one (the former is more than 9 times the latter). This is because the thermal conductivity and heat exchange area of the material used to make the rotating ring are both better than those of the stationary ring. In practice, the rotating ring plays a major role in heat dissipation.

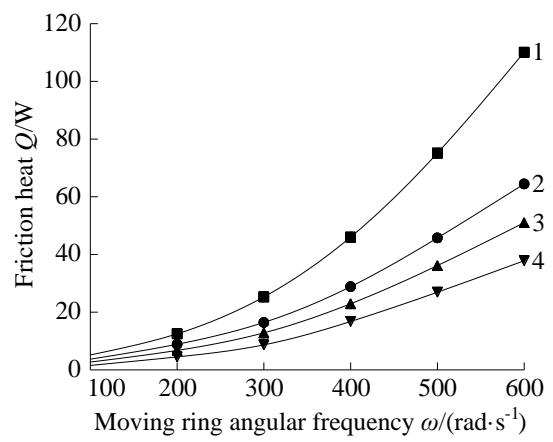

Figure 6. Relationship curve of the frictional heat and the angular frequency

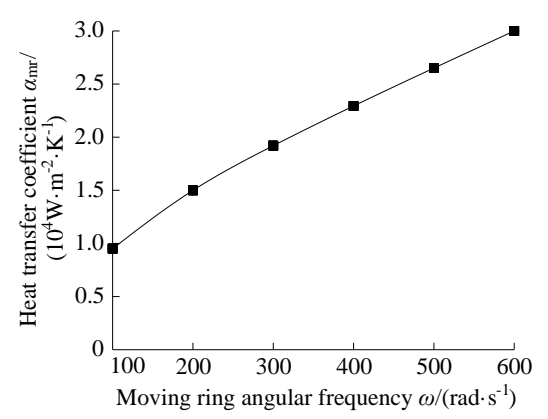

Figure 7. Relationship curve of the heat transfer coefficient of the rotating ring and the angular frequency

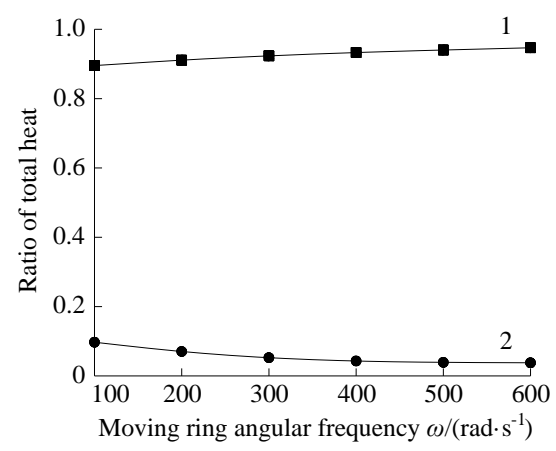

Figure 8. Ratio of the heat received by the rotating ring to that by the stationary ring

Fig.9 and Fig.10 respectively show the relationships between the inner diameter (ID)/outer diameter (OD) temperature change of the rotating ring face and the angular frequency and the thermal conductivity. As can seen from Fig. 9, with the angular frequency increasing, the ID/OD temperature of the rotating ring also increases on the whole. Due to the poor heat dissipation conditions of the end face ID material, the ID temperature of the rotating ring significantly increases when the mechanical seal face is subjected to friction [29], while there is only a slight increase in the OD temperature. When the difference between the ID and OD temperatures is too large, the mechanical seal face may experience serious friction, leading to a larger leakage rate and deformation of the end face [30].

From Fig.10, it can be seen that, when the thermal conductivity increases, the ID temperature of the rotating ring rapidly drops while the OD temperature sees only a slight drop, 
i.e. the greater the thermal conductivity of the material, the lower the temperature of the mechanical seal face.

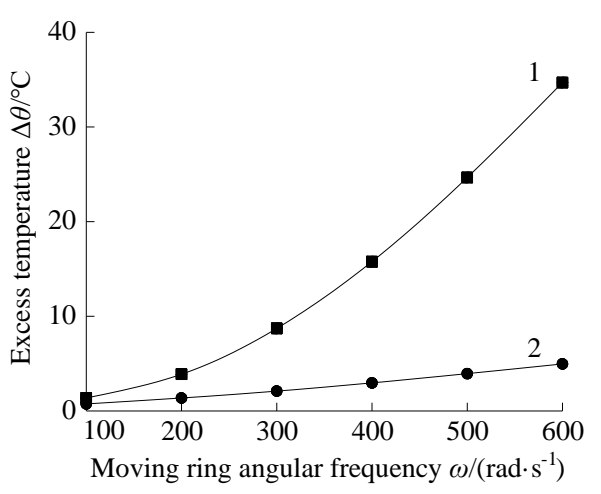

Figure 9. Relationship between the ID/OD temperature change and the angular frequency of the rotating ring face

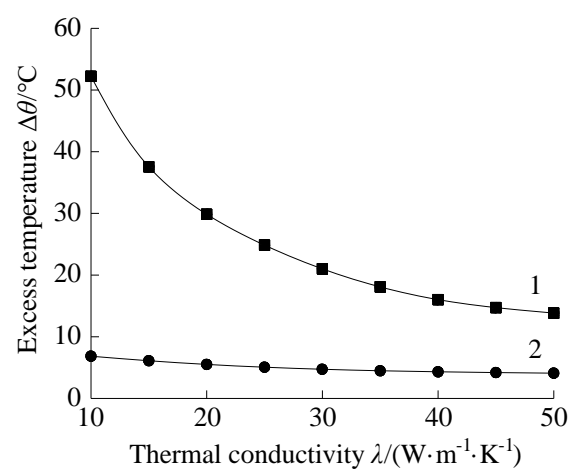

Figure 10. Relationship between the ID/OD temperature change and the thermal conductivity of the rotating ring face

\section{CONCLUSIONS}

This paper studies the liquid film flow characteristics and heat transfer characteristics of the mechanical seal face under the action of friction and thermal deformation through theoretical analysis. The conclusions are as follows:

(1) The mechanical seal face is deformed under the action of friction and mechanical force, and the liquid film flow characteristics of the end face changes. The liquid film pressure of the parallel flow channel increases linearly along the axial direction, and the liquid film pressure of the nonparallel flow channel exhibits a non-linear increase in a "convex" or "concave" direction; the leakage rate of the parallel flow channel is the smallest, followed by that of the convergent flow channel and then that of the divergent one. The liquid film bearing capacity of the convergent channel is the largest and that of the divergent one is the smallest. Overall, the performance of the parallel flow channel is the most stable. In the preliminary design of the mechanical seal, the form of contact between the rotating and stationary rings or the shape of the end face should be adjusted to ensure the flow channels are convergent.

(2) When the mechanical seal face is only subjected to the friction of the liquid film, the larger the angular frequency, the smaller the thickness of the liquid film, and the more heat generated by the friction. The heat transfer coefficient of the rotating ring is much greater than that of the stationary ring, so the heat absorption of the former is also significantly higher than that of the latter.

(3) When the angular frequency increases, the ID temperature of the rotating ring significantly increases, while the OD temperature increases at a smaller rate; when the thermal conductivity of the rotating ring increases, the ID temperature rapidly drops while the OD temperature sees almost no change.

\section{ACKNOWLEDGMENT}

This work is supported by National Science Foundation of China (Nos. 51605252 and 51876103) and Zhejiang Provincial Natural Science Foundation (No. LY18E090007)

\section{REFERENCES}

[1] Cicone T, Pascovici MD, and Tournerie B. (2001). Nonisothermal performance characteristics of fluid film mechanical face seals. ARCHIVE Proceedings of the Institution of Mechanical Engineers Part J Journal of Engineering Tribology 1994-1996 (vols 208-210) 215(1): 35-44. https://doi.org/10.1243/1350650011541729

[2] Peng XD, Xie YB, and Gu YQ. (2006). Simpler method for volatile medium pump mechanical seals. Proceedings of the Institution of Mechanical Engineers -- Part J 220(7): 643-647. https://doi.org/10.1243/13506501j03104

[3] Wang YM, Wang JL, Yang HX, Jiang N, Sun XK. (2004). Theoretical analyses and design guidelines of oil-filmlubricated mechanical face seals with spiral grooves. A S L E Transactions 47(4): 537-542. https://doi.org/10.1080/05698190490500743

[4] Ma G, Zhao W, Shen XM. (2012). Effect of surface roughness on performance of spiral groove gas film face seal. Applied Mechanics \& Materials 184-185: 180-183. https://doi.org/10.4028/www.scientific.net/amm.184185.180

[5] Brunetiere N. (2014). The lubrication regimes of mechanical face seals. Applied Mechanics \& Materials 630:

255-266. https://doi.org/10.4028/www.scientific.net/amm.630.25 5

[6] Zhou J, and Boqin GU. (2007). Characteristics of fluid film in optimized spiral groove mechanical seal. Chinese Journal of Mechanical Engineering 20(6): 54-61. https://doi.org/10.3901/cjme.2007.06.054

[7] Zhang ZS, Yang YM, Dai XD, Xie YB. (2013). Effects of thermal boundary conditions on plain journal bearing thermohydrodynamic lubrication. Tribology Transactions $\quad 56(5)$ : 759-770. https://doi.org/10.1080/10402004.2013.797531

[8] Ionescu M, Mihai I. (2010). Analytical model of thermohydrodynamic estimation of slider bearing. Lubrication Science 22(10): 479-485. https://doi.org/10.1002/ls.129

[9] Yang H. (2005). Experimental investigations and field applications of oil-film-lubricated mechanical face seals with spiral grooves. Tribology Transactions 48(4): 589596. https://doi.org/10.1080/05698190590948232

[10] Wada S, Hashimoto H, Nakagawa T. (2008). Thermohydrodynamic lubrication of journal bearings in 
turbulent flow. Bulletin of Jsme 23(179): 773-780. https://doi.org/10.1299/jsme1958.23.773

[11] Migout F, Brunetière N, Tournerie B. (2015). Study of the fluid film vaporization in the interface of a mechanical face seal. Tribology International 92: 84-95. https://doi.org/10.1016/j.triboint.2015.05.029

[12] Gu BQ, Zhou JF, Ye C, Sun JJ. (2008). Frictional heat transfer regularity of the fluid film in mechanical seals. Science in China 51(5): 611-623. https://doi.org/10.1007/s11431-008-0045-5

[13] Luan Z, Khonsari MM. (2009). A thermohydrodynamic analysis of a lubrication film between rough seal faces. ARCHIVE Proceedings of the Institution of Mechanical Engineers Part J Journal of Engineering Tribology 19941996 (vols 208-210) 223(4): 665-673. https://doi.org/10.1243/13506501jet456

[14] Danos JC, Tournerie B, Frêne J. (2000). Notched rotor face effects on thermohydrodynamic lubrication in mechanical face seal. Tribology 38(00): 251-259. https://doi.org/10.1016/s0167-8922(00)80130-3

[15] Rouillon M, Brunetière N. (2018). Spiral groove face seal behaviour and performance in liquid lubricated applications. Tribology Transactions (3): 1-41. https://doi.org/10.1080/10402004.2018.1463426

[16] Huang ZP, Zhang Z, Zhang JK, Chen K, Fu P, Lin ZB. (2014). Research on the micro scope condition of end face of liquid-lubricated mechanical seals. Advanced Materials Research 898: 574-577. https://doi.org/10.4028/www.scientific.net/amr.898.574

[17] Lee D, Sun KH, Kim B, Kang D. (2018). Thermal behavior of a worn tilting pad journal bearing: thermohydrodynamic analysis and pad temperature measurement. Tribology Transactions (4): 1-38. https://doi.org/10.1080/10402004.2018.1469805

[18] Alyaqout SF, Elsharkawy AA. (2013). Optimum shape design for surface of a thermohydrodynamic lubrication slider bearing. Lubrication Science 25(6): 379-395. https://doi.org/10.1002/ls.1189

[19] Zhou JF, Gu BQ. (2007). Coupling analysis of fluid film and thermal deformation of sealing members in spiral groove mechanical seal. Key Engineering Materials 353358(353-358): 2455-2458. https://doi.org/10.4028/www.scientific.net/kem.353358.2455
[20] Brunetière N, Modolo B. (2009). Heat transfer in a mechanical face seal. International Journal of Thermal Sciences $\quad 48(4)$ : 781-794. https://doi.org/10.1016/j.ijthermalsci.2008.05.014

[21] Zhou J, Gu B. (2006). Analysis of thermal deformation of end face of mechanical seal ring and forecast based on bp ann. Journal of Chemical Industry \& Engineering 57(12): 2902-2907.

[22] Yu L, Yu SR. (2012). Heat transfer in a mechanical face seal. Advanced Materials Research 560-561: 91-99. https://doi.org/10.4028/www.scientific.net/amr.560561.91

[23] Zhou J. (2006). Effect of end face deformation on the characteristic of fluid film in mechanical seal. Lubrication Engineering 70(12): 81-84.

[24] Takami MR, Gerdroodbary MB, Ganji DD. (2017). Thermal analysis of mechanical face seal using analytical approach. $\quad 5: \quad 60-68$. https://doi.org/10.1016/j.tsep.2017.10.023

[25] Djamaï A, Brunetière N, Tournerie B. (2010). Numerical modeling of thermohydrodynamic mechanical face seals. Tribology Transactions 53(3): 414-425. https://doi.org/10.1080/10402000903350612

[26] Chen Z, Liu T, Li J. (2016). The effect of the o-ring on the end face deformation of mechanical seals based on numerical simulation. Tribology International 97: 278287. https://doi.org/10.1016/j.triboint.2016.01.038

[27] Cheng JH., Ge PQ, Liu M. (2002). Fem analysis and experi-mental study on tempera-ture field of mechanical seal ring. Journal of Shandong University of Technology 32(4): 385-388.

[28] Bo R. (2002). Numerical modeling of dynamic sealing behaviors of spiral groove gas face seals. Journal of Tribology 124(1): 186-195. https://doi.org/10.1115/1.1398291

[29] Xue J, Luo W, Liu Z, Wu Z, Wang J, Liao R. (2018). A criterion of negative frictional pressure drop in vertical twophase flow. Chemical Engineering Transactions 66: 415-420. https://doi.org/10.3303/CET1866070

[30] Wei F, Jiang B, Pan B. (2018). Frictional wear of potassium titanate whisker filled carbon fabric/epoxy composites. Chemical Engineering Transactions 66: 115-120. https://doi.org/10.3303/CET1866020 